\title{
42. On the Growth of Crystals in the Presence of Colloids.
}

\author{
By Haku KoIDE and Tokutarô NAKAMURA. \\ (Comm. by S. TsuBoI, M.I.A., April 12, 1943.)
}

In the course of his study of forest soil, T. Nakamura discovered the interesting fact that large well-formed cubic crystals of salt $(\mathrm{NaCl})$ crystallise out from salt solution poured on clayey forest soil. In connection with this discovery, we made an experimental study on the growth of crystals from solutions, and found that certain inorganic salts, such as $\mathrm{NaCl}, \mathrm{NH}_{4} \mathrm{Cl},\left(\mathrm{NH}_{4}\right)_{2} \mathrm{SO}_{4}$, and $\mathrm{Na}_{2} \mathrm{CO}_{3}$ tend to crystallise out in large well-formed crystals in the presence of colloids like clayey soil, gelatine, vegetable glue, humus, and silica sol. Since this fact is of special interest from the points of view of crystal chemistry and petrology, brief notes will be given on some results of our experiments just mentioned.

Salt was crystallised out from $\mathrm{NaCl}$ solution by evaporating water in the thermostadt at a temperature of about $50^{\circ} \mathrm{C}$, the following three kinds of solution being used ${ }^{1}$.

Sample No. 1: $5 \mathrm{~N}-\mathrm{NaCl}$ solution

Sample No. 2: $5 \mathrm{cc}$ of dry forest soil $+50 \mathrm{cc}$ of $5 \mathrm{~N}-\mathrm{NaCl}$ solution

Sample No. 3: $5 \mathrm{cc}$ of soil suspension $+0.5 \mathrm{~g} \mathrm{NaCl}$

Crystals of salt formed upon complete evaporation of the water from these three samples are characterised below:

Sample No. 1: The resulting salt crystals were skeletal and always small, usually less than $1.0 \mathrm{~mm}$ (Fig. 1).

Sample No. 2: In this sample, the salt appeared as large, wellformed cubic crystals, up to $7.0 \mathrm{~mm}$ across. embedded in clayey soil (Fig. 2).

Sample No. 3: Abundant large crystals of salt, up to $5.0 \mathrm{~mm}$ in diameter, were seen developed (Fig. 3). Under the microscope, they enclosed considerable fine particles of soil, with a tendency to be almost or wholly lacking in the core as well as along the crossed diagonals of the crystals (Fig. 4).

These experimental results suggest that colloids play an important role in the growth of salt crystals, though it is still to be studied how colloids affect the crystal growth.

Large well-formed porphyroblasts of certain minerals. e.g. andalusite, cordierite, etc., which are trequently found in metamorphosed pelitic sediments, exhibit features similar in many respects to those of the salt crystals formed in the above experiments. Figs. 5 and 6 show respectively purphyroblastic andalusite and potash-feldspar in meta-

1) At temperatures lower than about $15^{\circ} \mathrm{C}$, the salt tends to appear as small crystals, about $1.0 \mathrm{~mm}$ across, even under slow evaporation of the water. The temperature during crystallisation of salt therefore seems to be an important factor controlling the crowth of crystal-a subject that will be treated in another patper. 


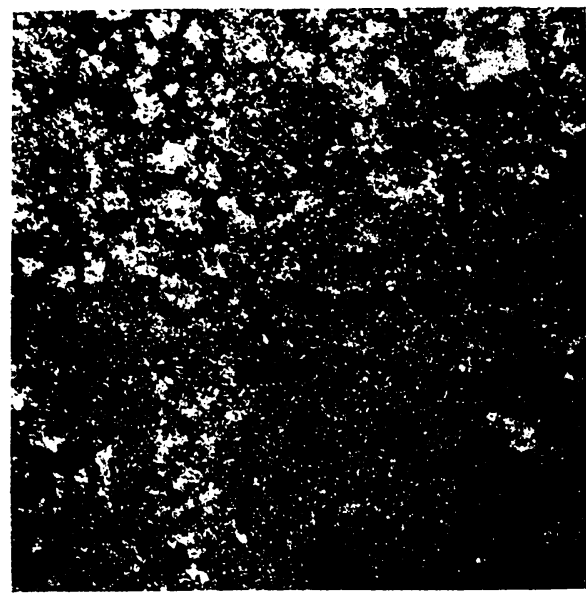

Fig. 1. $\times \frac{3}{2}$

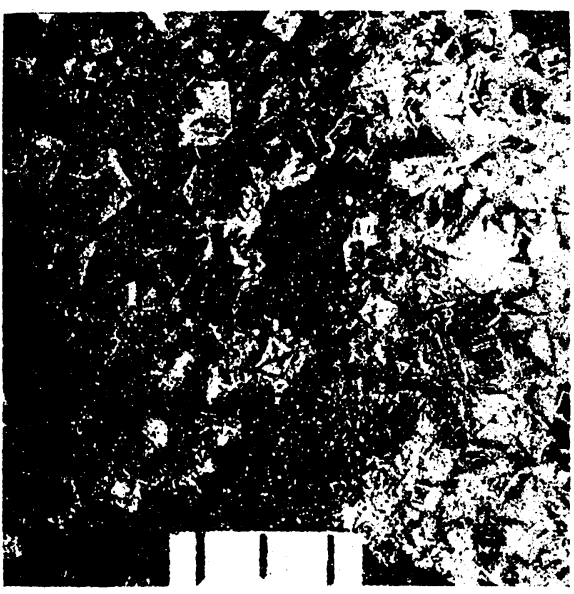

Fig. 3. $\times \frac{3}{2}$

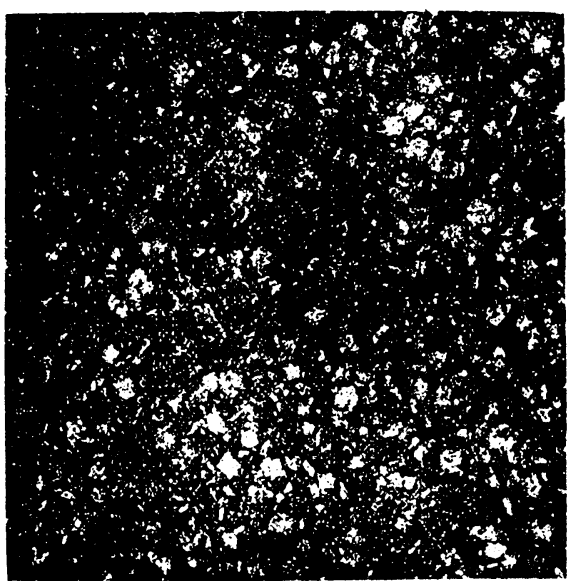

Fire $5 \times 2$

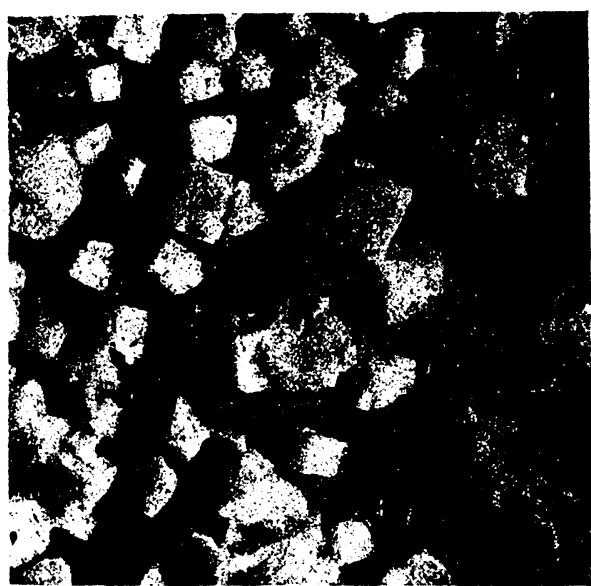

Fig. 2. $\times \frac{8}{2}$

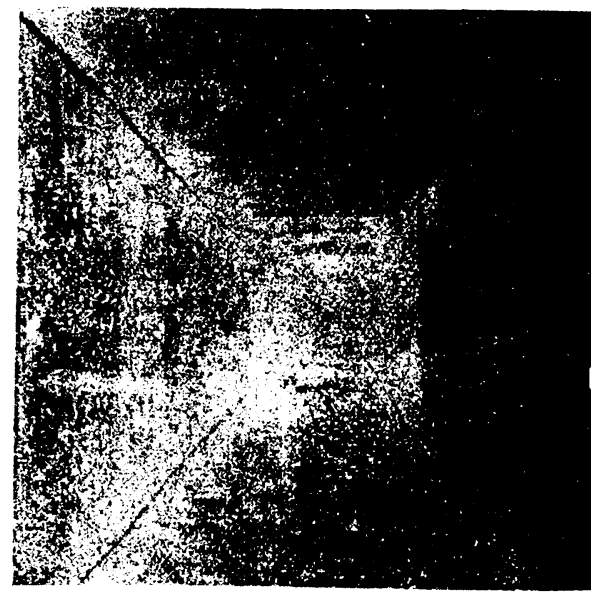

Fig $4 . \quad \times 35$

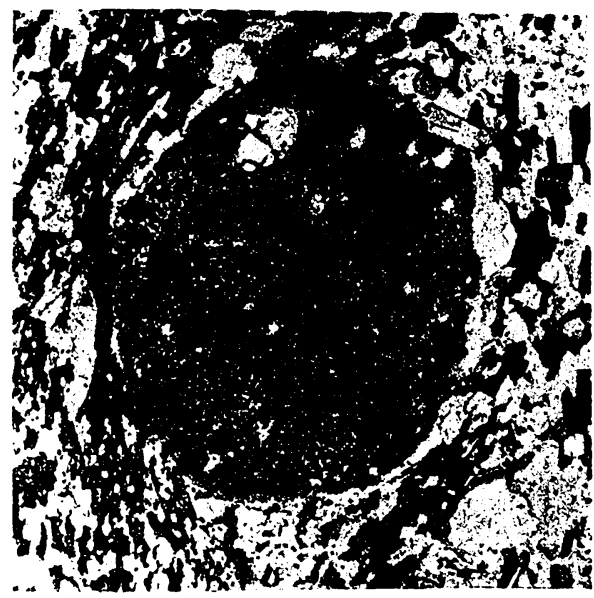

vin a $\sim 25$ 
morphosed pelitic sediments from Dando-san district, Aiti Prefecture. The porphyroblasts are often characterised by dusty and regularly arranged interpositions, mainly consisting of black carbonaceous matter. Moreover, they are found almost exclusively in fine pelitic sediments. From these it seems probable that the formation of certain porphyroblasts were faciliated by the presence of colloids, just as the formation of large well-formed cubic crystals of salt from $\mathrm{NaCl}$ solution.

The writers wish to record here their great indebtedness to Prof. Dr. Seitarô Tsuboi of the Geological Institute of Tokyo Imperial University for the valuable suggestions and for his kindness in reading the manuscript and also to Prof. Dr. Kentarô Nakamura of the Silvicultural Institute of the same University, where the experiments were carried on. 